\title{
Nephrotic syndrome in pregnancy: a case report
}

\author{
Ipsita Mohapatra, Subha R. Samantaray*
}

Department of Obstetrics and Gynecology, Prathima Institute of Medical Sciences, Karimnagar, Telangana, India

Received: 01 October 2020

Accepted: 10 November 2020

\section{*Correspondence:}

Dr. Subha R. Samantaray,

E-mail: drsubha2009@gmail.com

Copyright: (C) the author(s), publisher and licensee Medip Academy. This is an open-access article distributed under the terms of the Creative Commons Attribution Non-Commercial License, which permits unrestricted non-commercial use, distribution, and reproduction in any medium, provided the original work is properly cited.

\section{ABSTRACT}

Nephrotic syndrome is a spectrum of renal disorders in which proteinuria is a hallmark. When pregnancy is affected by nephrotic syndrome, the maternal and fetal outcome, as well as the required treatment, depends on the underlying cause and severity of the disease. Pregnant patients with nephrotic syndrome are more prone to develop pre-eclampsia, preterm birth, low birth weight babies and intrauterine fetal growth restriction. Here we are presenting a case report on pregnancy with nephrotic syndrome which was managed by multidisciplinary approach with successful outcome.

Keywords: Nephrotic syndrome, Proteinuria, Intrauterine growth restriction, Pre-eclampsia

\section{INTRODUCTION}

Proteinuria in pregnancy in increased amount is common and it may range from slight increase to nephrotic amounts. Nephrotic syndrome is a spectrum of renal disorders in which proteinuria is a hallmark. ${ }^{1}$ It is characterised by the following: proteinuria in excess of 3.5 gm/day, hypoalbuminemia $(<30 \mathrm{gm} / \mathrm{l})$, edema, hyperlipidemia, and renal biopsy may reveal the microscopic renal abnormalities.

Nephrotic range proteinuria developing during pregnancy may be due to underlying renal cause. Prompt diagnosis, adequate counselling and systemic management can lead to successful pregnancy outcome. ${ }^{2}$

Here we are presenting a case report on pregnancy with nephrotic syndrome which was managed by multidisciplinary approach with successful outcome.

\section{CASE REPORT}

A gravida 2 para 1 with one previous caesarean section was referred to our hospital at 32 weeks of gestation with anasarca. Her antenatal follow up at a local hospital was uneventful till 16 weeks of gestation. At 18 weeks she had complains of decreased urine output and urine examination revealed urinary tract infection. She was treated symptomatically. At 6th month of pregnancy, she developed pedal oedema which gradually progressed to anasarca through 8th month of gestation for which she was referred to our hospital.

At admission, patient had mild pallor and generalised oedema. Her blood pressure was $150 / 100 \mathrm{~mm}$ of mercury. Per abdomen examination revealed engorged veins, oedematous abdominal wall, moderate ascitis and 32 weeks size uterus. Obstetric ultrasound showed a single intrauterine pregnancy with mild intra uterine growth restriction. Fetal Doppler report showed mild raised indices in the uterine arteries.

Further work up showed severe hypoproteinemia with total serum albumin $2 \mathrm{gm} / \mathrm{dl}$. 24 hour urine examination showed massive proteinuria (4.6 gm/day). Renal function tests were within normal limits. Total cholesterol was 409 $\mathrm{mg} / \mathrm{dl}$ (hypercholesterolemia). Abdominal ultrasound revealed moderate ascitis, bilateral grade-1 parenchymal changes, mild hydronephrosis on right side and bulky pancreatic head. On basis of all these reports, patient was diagnosed with nephrotic syndrome complicating pregnancy. 
She was started on tablet spironolactone $(25 \mathrm{mg})$, tablet wysolone $(40 \mathrm{mg})$, tablet aspirin $(75 \mathrm{mg}$ ) and tablet nifedipine $(10 \mathrm{mg}$ twice a day). Serial monitoring of mother and foetus was done with periodic renal function tests, coagulation profile, daily non-stress test and twice weekly foetal Doppler. At 35 weeks patient complained of decreased foetal perception with foetal Doppler revealing absent diastolic flow in the umbilical artery. Caesarean section was planned and she delivered a female baby of 2 $\mathrm{kg}$ birth weight with good APGAR. Intraperitoneal drain was kept in view of ascitis.

On 1st post-operative day there was minimal urine output and drain collection was 3 litres. Forced diuresis with furosemide $40 \mathrm{mg}$ twice a day and albumin infusion was started on alternate days. She was also started on methyl prednisolone $(5 \mathrm{mg})$. Patient gradually improved and intraperitoneal drain was removed on 9th post-operative day. Sutures were removed on 12th post-operative day. Renal biopsy was deferred in view of unaffordability of the patient. She was discharged on 14th post-operative day. At discharge her serum albumin improved to $3 \mathrm{gm} / \mathrm{dl}$ and proteinuria gradually decreased to $650 \mathrm{mg} /$ day at the end of 3 months. Patient is in regular follow up with the treating nephrologist.

\section{DISCUSSION}

The main cause of proteinuria in pregnancy is preeclampsia. It should be considered the main cause of nephrotic syndrome unless otherwise proved. The various renal causes of nephrotic range proteinuria are membranoproliferative glomerulonephritis, immunoglobulin A (IgA) nephropathy, lupus nephritis, focal and segmental glomerulosclerosis, infection related glomerulonephritis, drug related glomerulonephritis etc.

When pregnancy is affected by nephrotic syndrome, the maternal and fetal outcome, as well as the required treatment, depends on the underlying cause and severity of the disease. The coexistence of pregnancy and nephrotic syndrome is infrequent and incidence varies from 0.012 $0.025 \% .^{2}$ About $50 \%$ of women with nephrotic syndrome have increased protein excretion during pregnancy. ${ }^{3}$ In spite of this, nephrotic syndrome patients with pregnancy have usually better glomerular filtration rate. ${ }^{4}$ But pregnancy associated with membranoproliferative glomerulonephritis has an increased risk of fetal loss and also poor prognosis of maternal renal functions. ${ }^{5}$ Most patients with nephrosis who don't have severe hypertension or renal insufficiency have better pregnancy outcome. Patients with renal insufficiency or moderate to severe hypertension or both have a guarded prognosis. Fetal outcome is also poor in these cases. A third of these infants are reported to be intrauterine growth restricted as seen in our case. ${ }^{6}$

Proper investigations and follow up is necessary in these cases. Elevated parameters of serum creatinine are a risk factor for adverse pregnancy outcomes. ${ }^{7}$ Our patient had serum creatinine value of $1.1 \mathrm{mg} / \mathrm{dl}$ which worsened to 1.3 $\mathrm{mg} / \mathrm{dl}$ in the post delivery period.

Our patient had increased proteinuria (4.6 gm/24 hours). Liu et al had shown an association between level of proteinuria and unfavourable pregnancy outcomes in patients with IgA nephropathy. ${ }^{8}$ Pregnancies with lupus nephritis having proteinuria $>0.5 \mathrm{gm} /$ day also have a poor prognosis. ${ }^{9}$ For confirmation of the underlying aetiology renal biopsy needs to be done which was not done in our patient due to financial strains.

Treatment protocol has to be decided by multidisciplinary team. Steroids are the mainstay of treatment. Calibration of steroids has to be done based on the 24 hours urine protein flux. Our case well tolerated steroids with steady blood sugar levels. In our case, patient developed hypertension in the last trimester which was controlled by calcium channel blockers.

Pregnant patients with nephrotic syndrome are more prone to develop pre-eclampsia, preterm birth, low birth weight babies and intrauterine fetal growth restriction. ${ }^{10}$ Our patient was diagnosed with mild intrauterine fetal growth restriction at 32 weeks of gestation. Pregnancy was terminated at 35 weeks of gestation in view of decreased fetal perception and absent flow in the umbilical artery. Pregnant patients with nephrotic syndrome need to be regularly monitored to avoid any complications in pregnancy.

\section{CONCLUSION}

Nephrotic syndrome patients need to be managed by efficient multidisciplinary approach to optimize fetomaternal outcome. Pre-conceptional counselling is necessary and continuation of pregnancy is planned only when renal functions are well preserved and blood pressure is under control.

\section{Funding: No funding sources \\ Conflict of interest: None declared \\ Ethical approval: Not required}

\section{REFERENCES}

1. Macé C, Chugh SS. Nephrotic syndrome: components, connections and angiopoietin-like 4related therapeutics. J Am Soc Nephrol. 2014;25(11):2393-8.

2. Mishra V, Agarwal H, Lamba S, Chaudhary S, Roy P, Goel S. Maternal and perinatal outcome in a pregnancy with nephrotic syndrome. Int J Reprod Contracept Obstet Gynecol. 2017;6:2657-9.

3. Smyth A, Radovic M, Garovic VD. Women, kidney disease, and pregnancy. Adv Chronic Kidney Dis. 2013;20(5):402-10.

4. Fitzpatrick A, Mohammadi F, Jesudason S. Managing pregnancy in chronic kidney disease: improving 
outcomes for mother and baby. Int J women's Health. 2016;8:273-85.

5. Packham DK, North RA, Fairley KF, Whitworth JA, Kincaid-Smith P. Membranous glomerulonephritis and pregnancy. Clin Nephrol. 1987;28(2):56-64.

6. Motoyama O, Iitaka K. Pregnancy in 4 women with childhood-onset steroid-sensitive nephrotic syndrome. CEN Case Rep. 2014;3(1):63-7.

7. Hayslett JP, Reece EA. Managing diabetic patients with nephropathy and other vascular complications. Baillieres Clin Obstet Gynaecol. 1994;8(2):405-24.

8. Liu Y, Ma X, Lv J, Shi S, Liu L, Chen Y, et al. Risk factors for pregnancy outcomes in patients with $\operatorname{IgA}$ nephropathy: a matched cohort study. Am J Kidney Dis. 2014;64(5):730-6.
9. Park EJ, Jung H, Hwang J, Kim H, Lee J, Ahn JK, et al. Pregnancy outcomes in patients with systemic lupus erythematosus: a retrospective review of 62 pregnancies at a single tertiary center in South Korea. Int J Rheum Dis. 2014;17(8):887-97.

10. De Castro I, Easterling TR, Bansal N, Jefferson JA. Nephrotic syndrome in pregnancy poses risks with both maternal and fetal complications. Kidney Int. 2017;91(6):1464-72.

Cite this article as: Mohapatra I, Samantaray SR Nephrotic syndrome in pregnancy: a case report. Int J Reprod Contracept Obstet Gynecol 2020;9:5190-2. 